\title{
TCP and UDP Based Performance Analysis of AODV, DSR and DSDV Routing Protocols Under Different Traffic Conditions in Mobile AdHoc Networks
}

\author{
Barinderpal Singh ${ }^{1}$ and Rahul Hans ${ }^{2}$ \\ ${ }^{1}$ Research Scholar CSE Department DAV University Jalandhar Punjab \\ ${ }^{2}$ Assistant Professor CSE Department DAV University Jalandhar Punjab \\ ${ }^{1}$ barinderpal.singh013@gmail.com \\ ${ }^{2}$ rahulhans@gmail.com
}

\begin{abstract}
Routing protocol is the primary strategy to design any wireless network. In Mobile AdHoc Network many routing protocols are present for sending packets from source to destination. Routing protocols in Mobile AdHoc Networks (MANETs) are reactive routing protocols, proactive routing protocols, hybrid routing protocols. Performance analysis of different routing protocols is the major step before selecting the routing protocol. Routing protocols perform different under different traffic conditions in different environments. In this paper, the TCP and UDP based performance analysis is carried out in reactive routing protocols and proactive routing protocols with different packet size using NS2 simulator under different traffic conditions. The delay, throughput and packet delivery ratio are common measures parameters used for the comparison of performance of reactive protocols and proactive protocols.
\end{abstract}

Keywords: Mobile Adhoc Networks, TCP, UDP, FTP, CBR, AODV, DSR, DSDV, NS2, Delay, Throughput, Packet Delivery Ratio

\section{Introduction}

Mobile Ad-Hoc networks are highly dynamic networks characterized by the absence of physical infrastructure [1]. An AdHoc network consists of interconnected nodes which makes a network without any fixed infrastructure and can be arranged dynamically. In recent years, the interest on adhoc networks is at their high because of the availability of wireless communication devices. The ease of deployment and the infrastructure less nature of Mobile Ad hoc Networks (MANETs) make them highly desirable for the present day multimedia communications [10]. Multiple network hops are required to deliver and exchange data across a network [18]. Capabilities and limitations are to be concerned while designing adhoc network that the physical layer imposes on the network performance. The communication links in wireless network is unreliable so it is desired to come up with an integrated design of physical, MAC and network layer [7]. Dynamic and reliable protocols are required in MANETs, as they have no infrastructure (base stations) and their network topology changes frequently [2].

The primary objective of this paper is to analyze the performance of different routing protocols under different traffic conditions with different packet size. Through this paper it is find that how TCP and UDP will react under different network conditions [11]. The network performance of different protocols varies under different parameters. In order to achieve this, File Transfer Protocol (FTP) [12] and Constant Bit Rate (CBR) traffic conditions is used. In this emphasized on end to end delay, throughput and packet delivery ratio. The above parameters are validating with different network size, varying number of nodes. This analysis is done to check the quality of service provided by routing 
protocols under different traffic conditions with different packet size. This paper organized as a basic idea of routing protocols, tool used, simulation and performance analyses, results, conclusion and future work.

\section{MANETs Routing Protocols}

MANETs is made up of three words i.e. Mobile which means changeable or portable, AdHoc which means Temporary or for specific purpose, Networks which means Flexible data applications which use networks to communicate. MANETs is a wireless adhoc network which consists of self-governing nodes. These self-governing nodes communicate to each other without any preinstalled network and each node configures itself. In this infrastructure less (MANET) network the routing is a challenging work, because there is no fixed device, all are movable and each device act as a node as well as a router [21]. A major anxiety that affects such a network that characterized by dynamically changing topology is the performance, while routing with robustness performance is one of the key challenges in deploying MANET [15]. Many routing protocols have been proposed to accommodate the needs of communications for MANET [3]. Routing protocol is a standard used to determine the route path taken during the transmission of data [4]. Selecting an appropriate routing protocol for steering data packets is a very important issue to evaluate the performance of wireless mobile ad hoc networks (MANETs) [16]. In addition, the routing protocols that are usually exploited in MANETs are characterized as proactive (Table-driven) and reactive (On-demand) [17].

In this section Ad-hoc routing protocols such as Dynamic Source Routing (DSR), Adhoc On-Demand Distance Vector Routing (AODV) and Destination sequence Vector (DSDV) have been proposed to solve the multihop routing problem in Ad-hoc networks [6] and the key features of AODV, DSR and DSDV are briefly described. In MANETs Reactive and Proactive routing protocols are present. Reactive protocols are on demand protocol which means that it creates the connection only when needed. Routing protocols which comes under reactive protocols are AODV and DSR. Proactive protocols are table driven protocols which mean that the path is preinstalled or predefined.

\subsection{AdHoc on Demand Distance Vector (AODV)}

AODV is an adhoc on demand distance vector which is a type of reactive protocol. AODV is a Source drive type routing protocol [13]. In AODV the communication takes place only when desirable. In AODV a hop-to-hop methodology takes place. AODV is a combination of on demand and distance vector. On demand means the communication takes place only when needed and distance vector means a link-state protocol. In AODV a RREQ (Route Request) is send to each and every node in the network. When all intermediate nodes have a valid and appropriate route to the destination then the RREP (Route Reply) packets are sending to the source by the nodes or by the destination itself. If no valid route is finding by the nodes then the RERR (Route Error) is send to the source node.

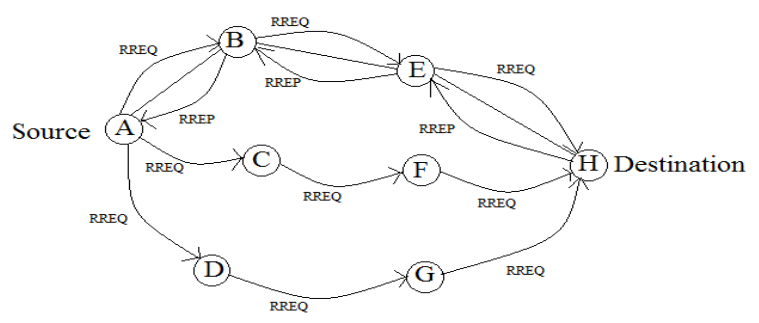

Figure 1. Working of AdHoc Routing Protocol 


\subsection{Dynamic Source Routing (DSR)}

DSR stands for Dynamic Source Routing and is a type of reactive protocol. DSR is an on demand protocol which is designed for use in multihop wireless network. DSR allows the network to be completely self-organizing and self configuring, without the need for any existing network infrastructure or administration [14]. The two major phases of the protocol is route discovery and route maintenance [9]. In DSR all nodes dynamically discover a route from source to the destination. A route request is send to all the multihop network nodes. Each data packet carries a header and list of all nodes which take part in route discovery. Routed packets contain the address of all the devices which traverse in route discovery.

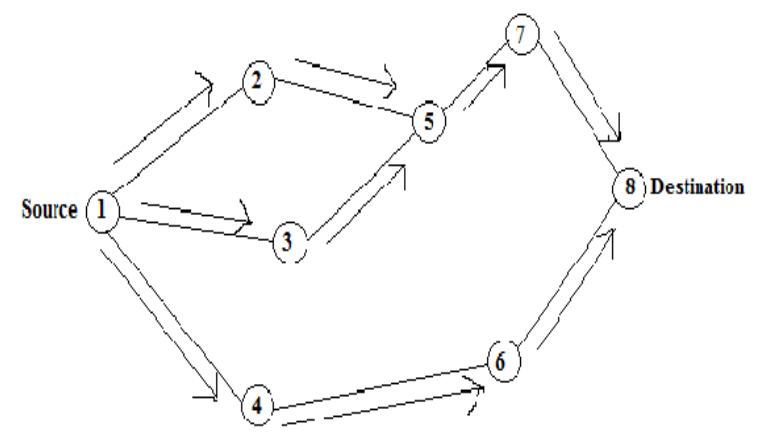

Figure 2. Propagation of Route Request (RREQ) Packet

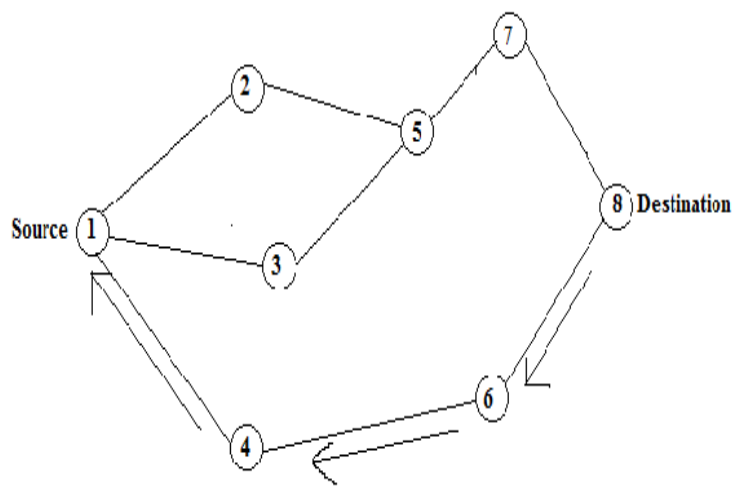

Figure 3. Propagation of Route Reply (RREP) Packet

\subsection{Destination Sequenced Distance Vector (DSDV)}

DSDV is a Destination Sequenced Distance Vector and is a type of proactive protocol. DSDV is a table driven approach which means that a route is predefined or preinstalled from source to destination. There is no need of route discovery in DSDV form source to destination. DSDV guarantees a loop free path to each destination without requiring nodes to participate in any complex update coordination protocol [8]. In DSDV protocol the path is update randomly. The data packets don't follow the same route for whole time it updates its path which consumes more bandwidth and more power. This route updating sometimes fully dump the network. 


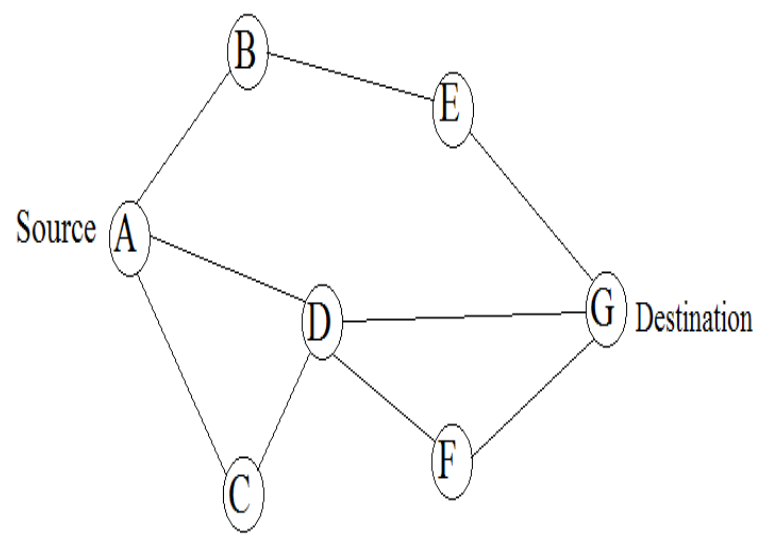

Figure 4. Working of DSDV Routing Protocol

\section{Simulation Methodology and Performance Metrics}

\subsection{Simulation Methodology}

Performance of routing protocols is different according to their working. To analyze the performance of routing protocols simulation is done. Simulation helps in analyzing the performance of routing protocols and performance of complex networks before apply in real applications. Routing protocols suffering from many problems like mobility, synchronization, localization, long route and other while routing. Therefore these protocols should be study in depth, simulated in different conditions and classified. This classification and simulation helps in understanding, comparing performances and assist researchers to differentiate the characteristics and define the pros and cons of routing protocols [22].The protocol whose performance is better we apply that protocol in real applications. To carry out the simulation several simulators are available which gives outputs according to the performance. In this work, the detailed study and simulation model using Network Simulator (NS-2.35) with different traffic models are presented [19] and AWK script is conducted to analyze the performance.

\subsection{NS2 (Network Simulator)}

NS2 is the tool which is used to carry out the performances of routing protocols of wired and wireless networks. It is a discrete event network simulator [20]. In our approach the NS2 tool is used to carry out the performances of AODV, DSR and DSDV routing protocols under different parameters. NS2 is simply an event driven simulation tool that has proved useful in studying the nature of communication networks. The main components of NS2 which is used for performance analysis are: NS, Tcl/Tk, Nam, Zlib, Xgraph, Awk.

The Ns2 all in one suite can be installed in the Unix-based machine by simply running the install script and following the instructions. Firstly we installed the NS2 and the corresponding components and then validate which verify the essential functionalities of all installed components. In NS2 simulator several models are available in this work we consider the following models:

\subsubsection{Node Model}

Node model is for energy source, memory capacity, processing capabilities etc. Firstly we create a new model then define it after defining validates the model and use it. 


\subsubsection{Node Deployment Model}

Node deployment model is for placement of nodes and its position a uniform model. The position of nodes given according to network area and movement of nodes at different speed.

\subsubsection{Node Mobility Model}

Node Mobility Model is for dynamic network topologies as Random Waypoint Mobility model. In this work Random Waypoint Mobility model is used which is a random model for the movement of nodes, and how their location, velocity and acceleration change over time.

\subsubsection{Radio Mobile}

Radio model for characteristics of radio used by node with a proper frequency, bandwidth, MAC layer functionality as IEEE 802.11 MAC model.

\subsubsection{Wireless Signal Propagation Model}

Wireless Signal Propagation model for SNIR (Signal to Noise Plus Interference Ration) at receiver as Two Ray Ground Propagation model. This model as the propagation phenomenon that results in radio signals reaching the receiving antenna.

\subsubsection{Packet Loss Model}

Packet Loss model is for packet loss or packet drop in model.

\subsubsection{Traffic Model}

Traffic is for traffic that nodes send to destination. The traffic model used in this work is CBR and UDP Model.

\subsection{AWK Script}

Text Processing and Data Extraction of the performance of protocols is necessary to analyze the performance of protocols and it is done by an interpreted programming language called AWK. AWK is designed for text processing and typically used as a data extraction and reporting tool [5]. AWK programs are data driven. The awk script is run according to following command:

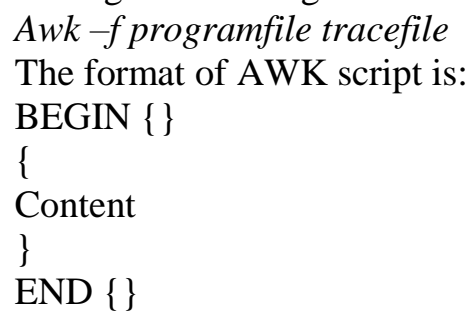

\subsection{Simulation Methods and Parameters}

The goal of our experiment is to examine and analyze the effect of different traffic conditions with various factors and parameters on the performance of adhoc networks. A major issue that affects such a network with dynamically changing topology is the performance since the nodes have both limited battery life and communicate in a 
bandwidth constrained network [23]. The effect of different traffic condition with different packet size is different on the performance of routing protocols in MANETs. In this work the performance of AODV, DSR and DSDV is analyze under different traffic conditions with different packet sizes.

\subsection{Performance Metrics}

The performance metrics helps in determining the behaviour and performance of routing protocols to achieve the quality of service (QOS). Performance Metrics measures the activities and performance of routing protocols.

\subsubsection{End-to-End Delay}

It is the time taken by the data packet to transmit across the network from source to destination. End-to-End delay depends on following components:

- $\quad$ Transmission Delay (TD)

- $\quad$ Propagation Time $(P T)$

- $\quad$ Processing Delay $(P D)$

- $\quad$ Queuing Delay $(Q D)$

Formula of End-to-End Delay is:

End-to-End Delay $=T D+P T+P D+Q D$.

\subsubsection{Throughput}

Throughput is the successfully data delivery over a communication network. It is the sum of the data rates that are delivered to all the terminals in a network. Formula of Throughput is:

Throughput $=$ received data $* 8 /$ data transmission period .

\subsubsection{Packet Delivery Ratio (PDR)}

The ratio of packets that are successfully delivered to a destination compared to the number of packets that have been sent out by the source. Formula to calculate Packet Delivery Ratio is:

Packet Delivery Ratio $=$ received packets/generated packets $* 100$. 


\section{Result Analysis}

4.1. Performance Analysis by Varying Network Size under TCP and CBR Traffic with 512 Bytes and 1000 Bytes Packet Size.

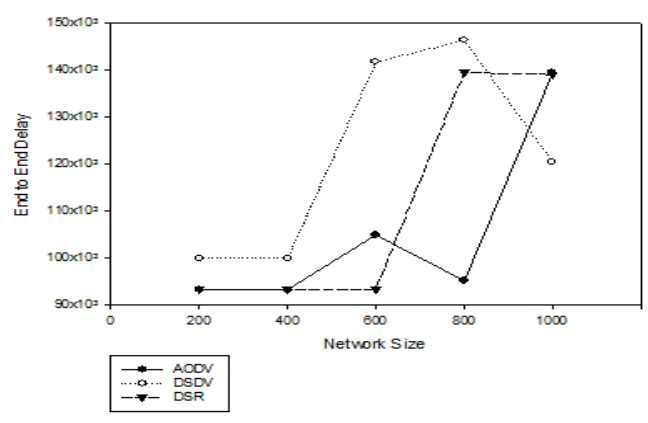

(a) End-to-end Delay (512 bytes)

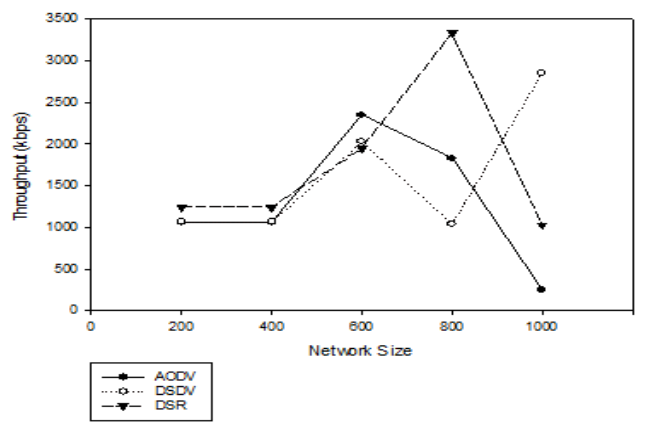

(c) Throughput (512 bytes)

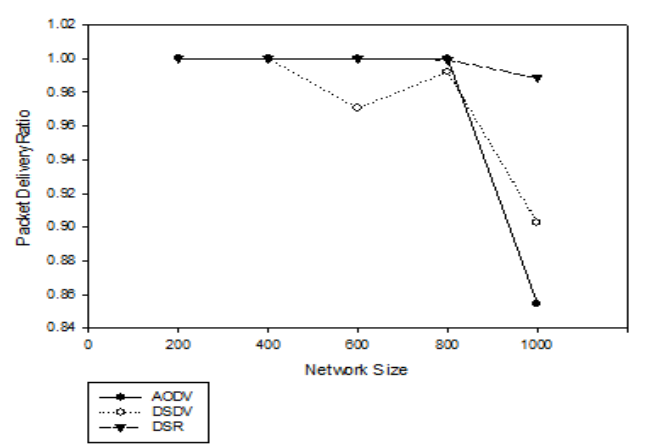

(e) Packet Delivery Ratio (1000 bytes)

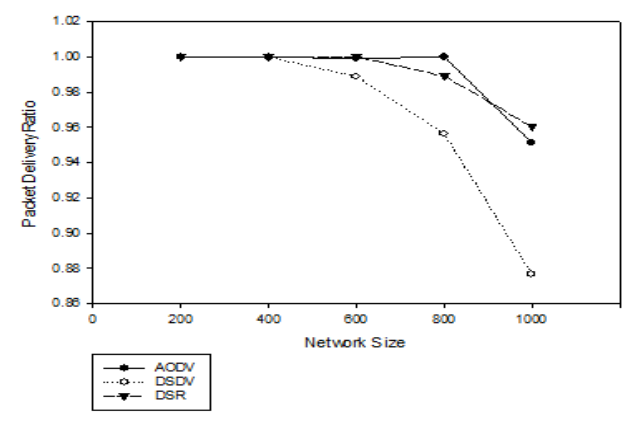

(b) Packet Delivery Ratio (512 bytes)

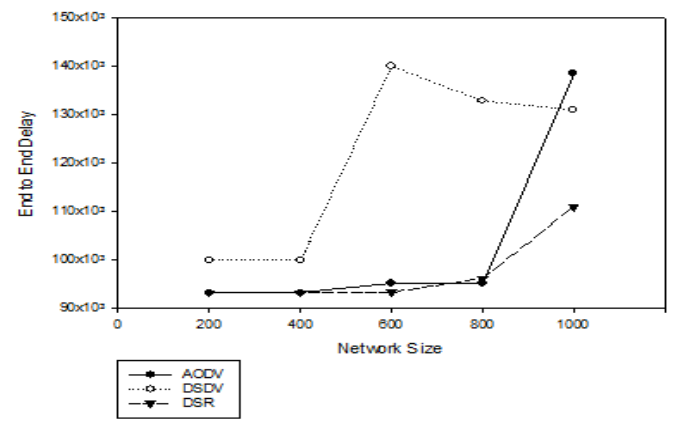

(d) End-to-End Delay (1000 bytes)

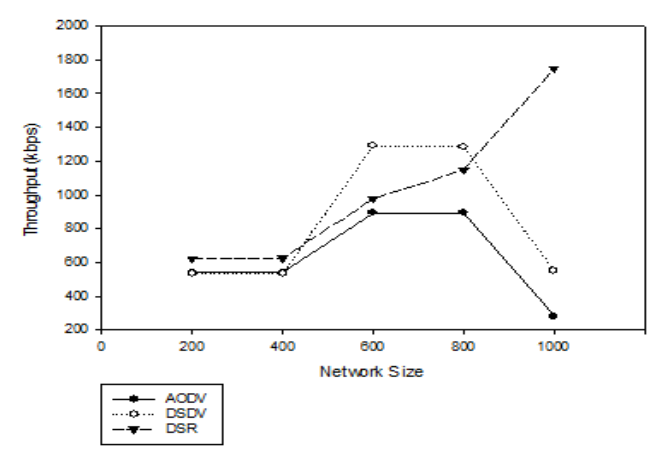

(f) Throughput (1000 bytes)

Figure 5. Performance Analysis Under TCP and CBR Traffic by Varying Network Size and Packet Size (a) Variation of End-to-End Delay (512 bytes) (b) Variation of Packet Delivery Ratio (512 bytes) (c) Variation of throughput (512 bytes) (d) Variation of End-to-End Delay (1000 bytes) (e) Variation of Packet Delivery Ratio (1000 bytes) (f) Variation of throughput (1000 bytes)

\subsubsection{Network Size Analysis}

The performance analysis is done by varying network size i.e. $200 \times 200$ sqm, 400x400 sqm, $600 \times 600 \mathrm{sqm}, 800 \times 800 \mathrm{sqm}, 1000 \times 1000 \mathrm{sqm}$. The routing protocols perform different under different network size which has effect on the performance of routing protocols. Packet size also effect the performance of routing protocols as the packet size 
increases the throughput decreases. In Figure 5 the variation of end to end delay, packet delivery ratio and throughput is carried out with different packet sizes and under TCP and CBR traffic conditions. In Figure 5 (a) variation of end to end delay is shown with 512 bytes packet size in which delay is more in DSDV routing protocol as the network size increases. AODV routing protocol delay less packets and DSR routing protocol lies between DSDV and AODV routing protocol. In Figure 5 (d) the variation of delay is shown with packet size 1000 bytes. In this variation of delay with packet size 1000 bytes the DSDV protocol delay more packets and DSR routing protocol delay less packet. In Figure 5 (b) variation of packet delivery ratio is shown with packet size 512 bytes. As the network size increase the packet delivery ratio of AODV, DSDV and DSR routing protocols decreases. The packet delivery ratio of DSDV routing protocol is low as compare to AODV and DSR routing protocol. The packet delivery ratio of AODV routing protocol is more which means it delivers more packets when packet size is 512 bytes. In Figure 5 (e) the packet delivery ratio with 1000 bytes packet size is shown. With packet size 1000 bytes the DSR routing protocol delivers more packets that means its packet delivery ratio is more as compare to AODV and DSDV routing protocols. Figure 5 (c) the variation of throughputs for AODV, DSDV and DSR routing protocols is shown with packet size 512 bytes. The DSR routing protocol gives more. The AODV routing protocol gives more throughput when network size is $600 \times 600 \mathrm{sqm}$. The DSDV routing protocol gives less throughput. In Figure 5 (f) the variation of throughput with packet size 1000 bytes is shown. AODV routing protocol gives less throughput when packet size is more i.e. 1000 bytes and the throughput of DSR routing protocol increases as the network size increases.

\subsection{Performance Analysis by Varying Network Size under TCP and FTP Traffic with 512 Bytes and 1000 Bytes Packet Size}

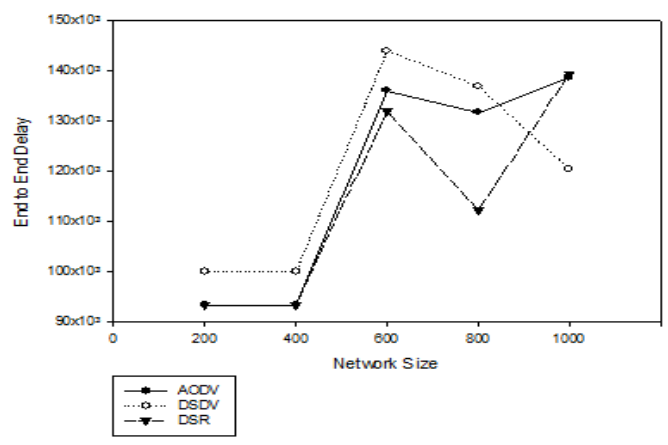

(a) End-to-End Delay (512 bytes)

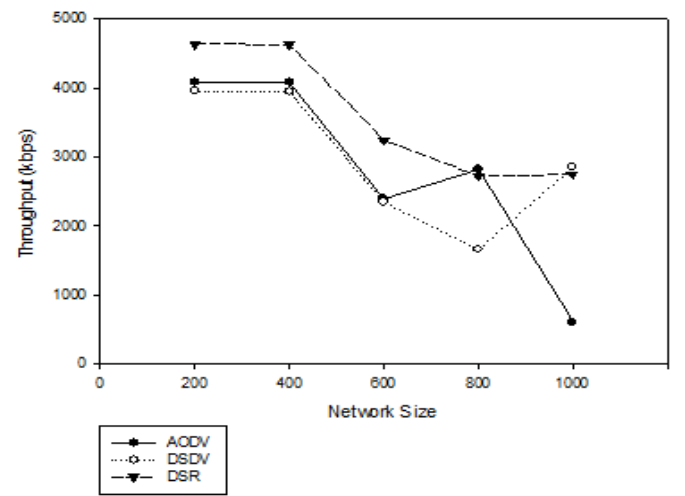

(c) Throughput (512 bytes)

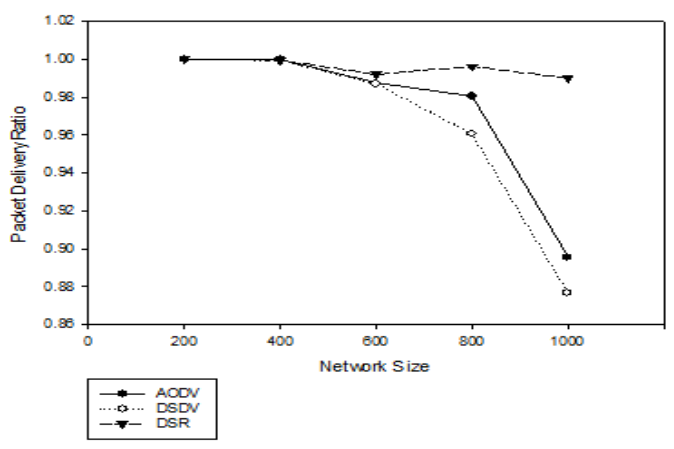

(b) Packet Deliver Ratio (512 bytes)

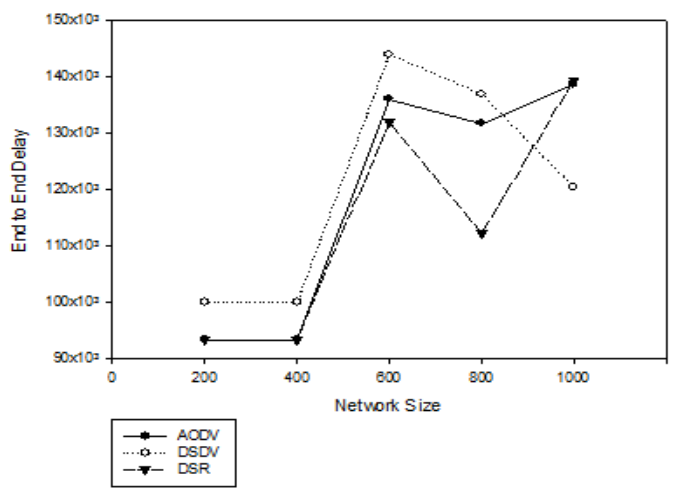

(d) End-to-End Delay (1000 bytes) 


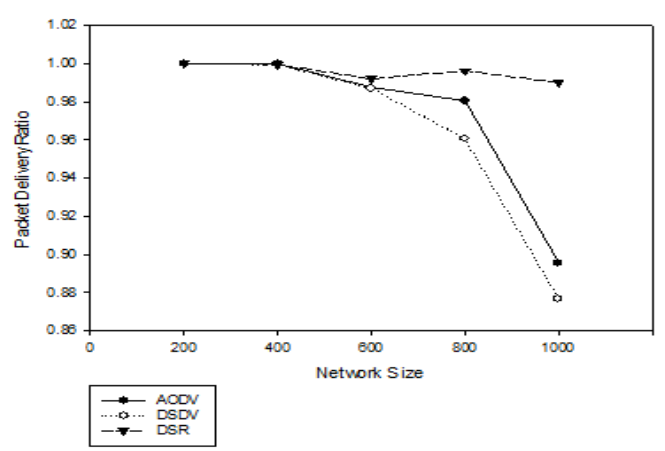

(e) Packet Delivery Ratio (1000 bytes)

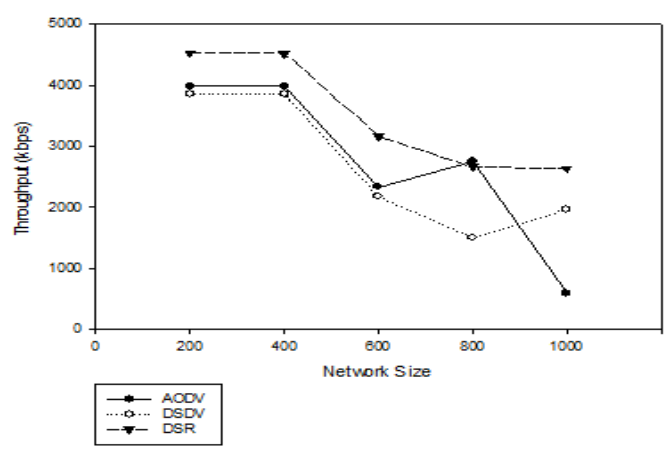

(f) Throughput (1000 bytes)

Figure 6. Performance Analysis under TCP and FTP Traffic by Varying Network Size and Packet Size (a) Variation of End-to-End Delay (512 bytes) (b) Variation of Packet Delivery Ratio (512 bytes) (c) Variation of throughput (512 bytes) (d) Variation of End-to-End Delay (1000 bytes) (e) Variation of Packet Delivery Ratio (1000 bytes) (f) Variation of throughput (1000 bytes)

\subsubsection{Network Size Analysis}

In Figure 6 the variation of end to end delay, packet delivery ratio and throughput is carried out with different packet sizes and under TCP and FTP traffic conditions. In Figure 6 (a) and 6 (d) variation of end to end delay is shown with 512 bytes and 1000 packet size in which delay is more in DSDV routing protocol when the network size is $200 \times 200 \mathrm{sqm}, 400 \times 400 \mathrm{sqm} .600 \times 600 \mathrm{sqm}$. 800 and $800 \mathrm{sqm}$. AODV routing protocol and DSR routing protocol delay less packets when network size is from 200x200 sqm to $800 \times 800$ sqm. In Figure 6 (b) and 6 (e) variation of packet delivery ratio is shown with packet size 512 bytes and 1000 bytes. Again in packet delivery ratio there is no effect of packet size on performance of AODV, DSDV and DSR routing protocols. The packet delivery ratio remains the same for both packet sizes. The packet delivery ratio is more for DSR routing protocol and less for DSDV routing protocol and AODV routing protocol lies in between DSR and DSDV routing protocol. Figure 6 (c) the variation of throughputs for AODV, DSDV and DSR routing protocols is shown with packet size 512 bytes. The DSR routing protocol gives more throughput then DSDV and AODV routing protocols. In Figure 6 (f) the variation of throughput with packet size 1000 bytes is shown. DSR routing protocol gives more throughput and DSDV routing protocol gives less throughput with packet size $1000 \times 1000$ bytes.

4.3. Performance Analysis by Varying Network Size under UDP and CBR Traffic with 512 Bytes and 1000 Bytes Packet Size.

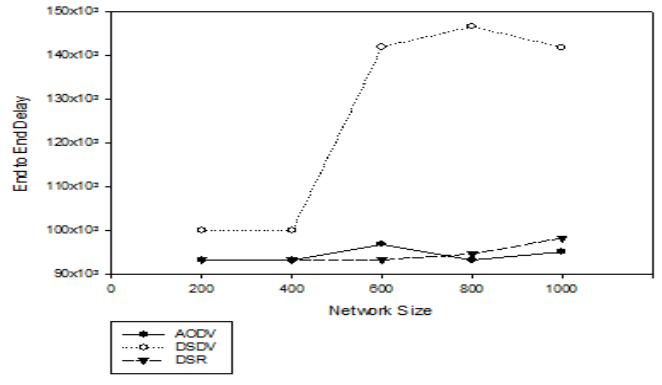

(a) End-to-End Delay (512 bytes)

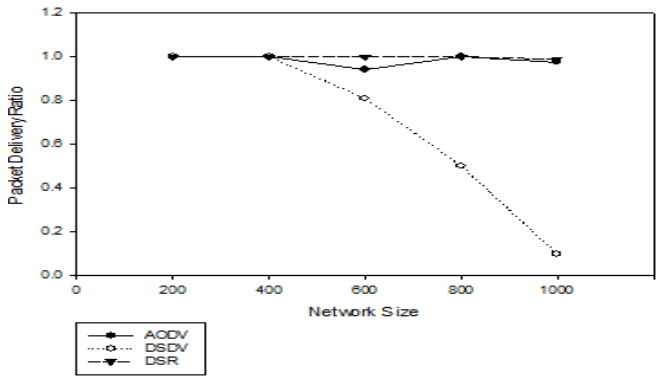

(b) Packet Delivery Ratio (512 bytes) 


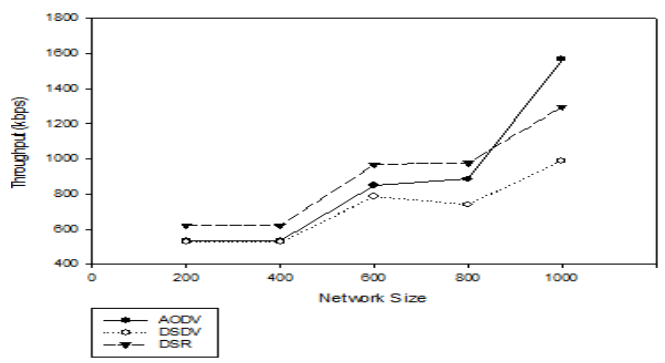

(c) Throughput (512 bytes)

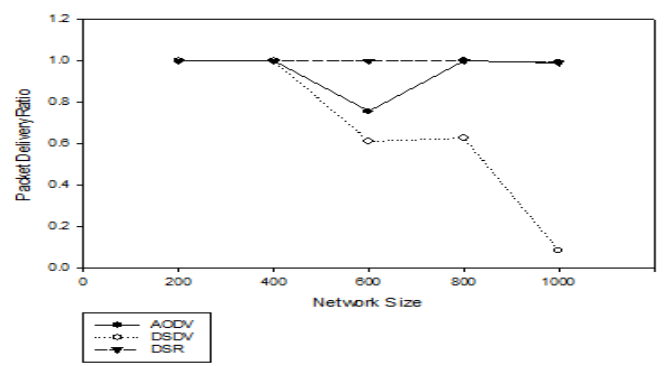

(e) Packet Delivery Ratio (1000 bytes)

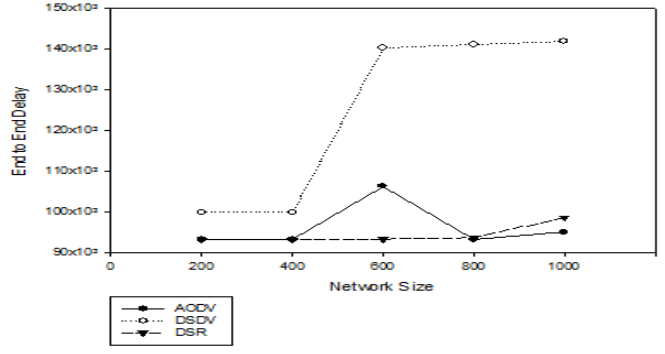

(d) End-to-End Delay (1000 bytes)

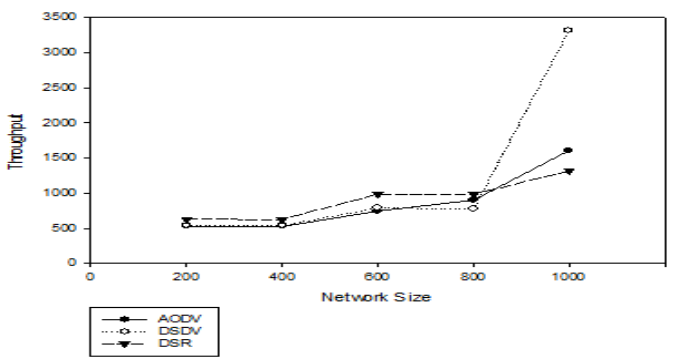

(f) Throughput (1000 bytes)

Figure 7. Performance Analysis under UDP and CBR Traffic by Varying Network Size and Packet Size (a) Variation of End-to-End Delay (512 bytes) (b) Variation of Packet Delivery Ratio (512 bytes) (c) Variation of throughput (512 bytes) (d) Variation of End-to-End Delay (1000 bytes) (e) Variation of Packet Delivery Ratio (1000 bytes) (f) Variation of throughput (1000 bytes)

\subsubsection{Network Size Analysis}

Figure 7 shows the variation of end to end delay, packet delivery ratio and throughput is carried out with different packet sizes and under UDP and CBR traffic conditions. In Figure7 (a) variation of end to end delay is shown with 512 bytes packet size in which delay is more in DSDV routing protocol as the network size increases, DSR routing protocol delay less packets. In Figure 7 (d) the variation of delay is shown with packet size 1000 bytes. Again the delay in DSDV routing protocol is more and less in DSR routing protocol. The delay of AODV routing protocols varies with network size but remains in between DSDV and DSR routing protocols. In Figure 7 (b) variation of packet delivery ratio is shown with packet size 512 bytes. The packet delivery ratio of DSR routing protocol is more. DSDV routing protocol delivers very less packets from source to destination so its packet delivery ratio is less. In Figure 7 (e) the packet delivery ratio with 1000 bytes packet size is shown. With packet size 1000 bytes the DSR routing protocol delivers more packets that means its packet delivery ratio is more as compare to AODV and DSDV routing protocols. Figure 7 (c) the variation of throughputs for AODV, DSDV and DSR routing protocols are shown with packet size 512 bytes. The DSR routing protocol gives more throughput. The DSDV routing protocol gives less throughput as compared to DSR and AODV routing protocols. In Figure 7 (f) the variation of throughput with packet size 1000 bytes is shown. AODV routing protocol gives less throughput when packet size is more i.e., 1000 bytes and the throughput of DSR routing protocol increases as the network size increases. 
4.4. Performance Analysis by Varying Number of Nodes under TCP and CBR Traffic with 512 Bytes and 1000 Bytes Packet Size

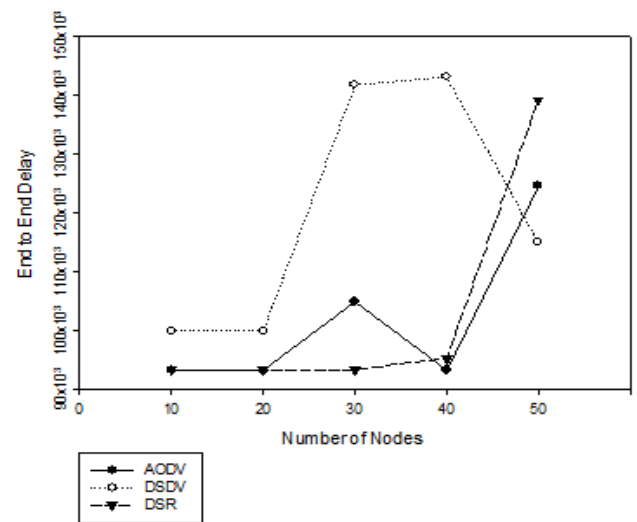

(a) End-to-End Delay (512 bytes)

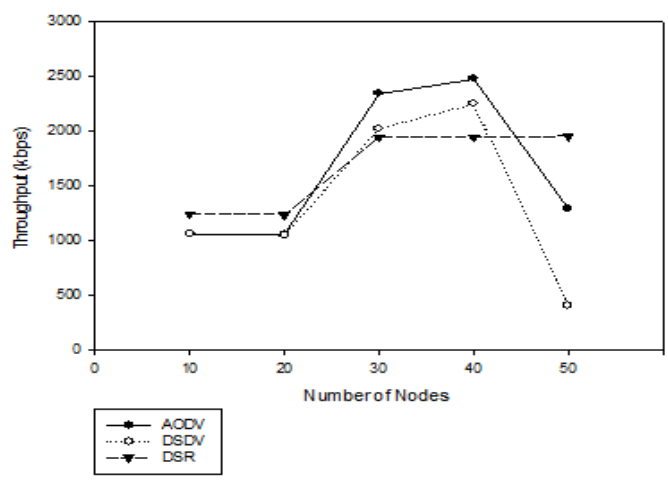

(c) Throughput (512 bytes)

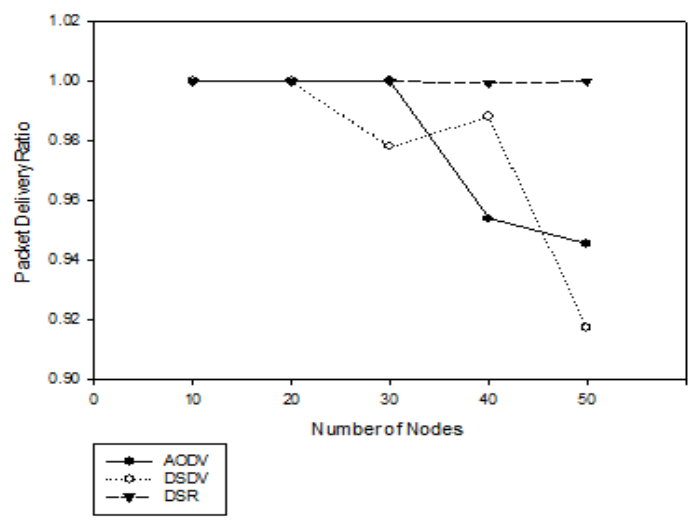

(e) Packet Delivery Ratio (1000 bytes)

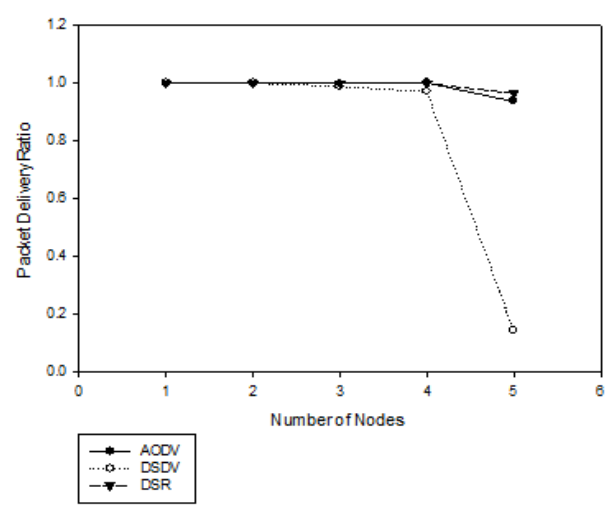

(b) Packet Delivery Ratio (512 bytes)

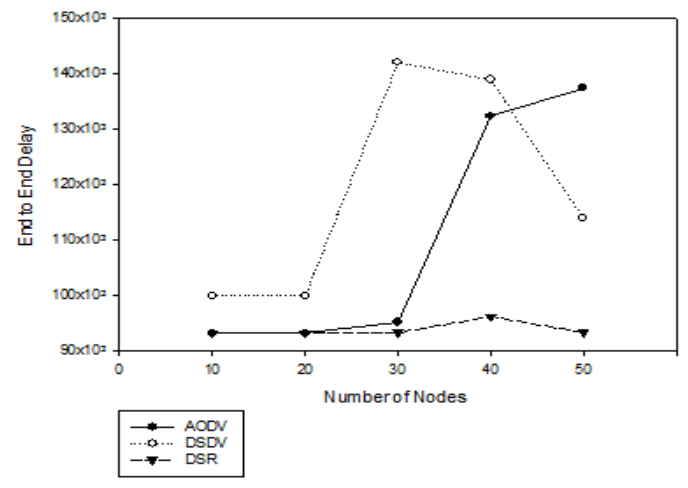

(d) End-to-End Delay (1000 bytes)

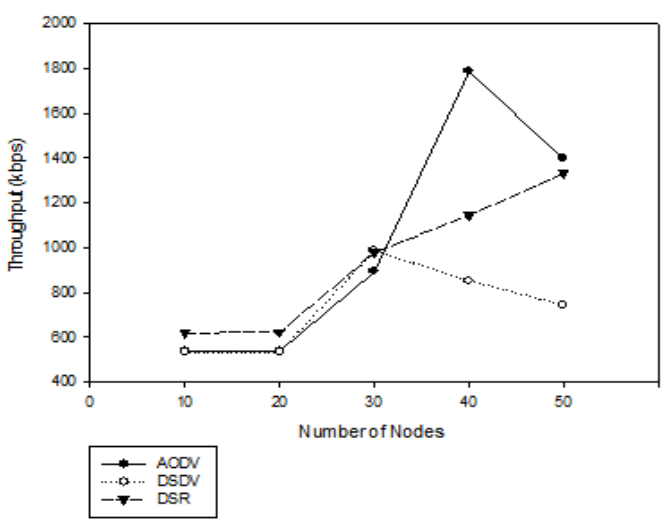

(f) Throughput (1000 bytes)

Figure 8. Performance Analysis under TCP and CBR Traffic by Varying Number of Nodes and Packet Size (a) Variation of End-to-End Delay (512 bytes) (b) Variation of Packet Delivery Ratio (512 bytes) (c) Variation of throughput (512 bytes) (d) Variation of End-to-End Delay (1000 bytes) (e) Variation of Packet Delivery Ratio (1000 bytes) (f) Variation of throughput (1000 bytes) 


\subsubsection{Number of Node Analysis}

The performance analysis is done by varying number of nodes from 10 to 50 . The number of nodes also affects the performance of routing protocols. In this the performance analysis of AODV, DSR and DSDV routing protocol carried out under different traffic conditions with different packet sizes. Figure 8 shows the performance analysis of AODV, DSR and DSDV routing protocol under TCP and CBR traffic by varying number of nodes with different packet sizes. In Figure 8 (a) the variation of Endto-End Delay is shown with packet size 512 bytes. The delay is more in DSDV routing protocol and increases as the number of nodes increases. The delay of DSR routing protocol is less. The delay of AODV routing protocol lies between DSR and DSDV routing protocols. In Figure 8 (d) the variation of End-to-End delay is shown with packet size 1000 bytes. Again the delay in DSDV routing protocol is more up to 40 numbers of nodes. The delay in DSR routing protocol is less then both DSDV and AODV routing protocol. Figure 8 (b) shows the variation of Packet Delivery Ratio with packet size 512 bytes. The packet delivery ratio of DSR and AODV routing protocols is almost same but more in DSR routing protocol. The packet delivery ratio in DSDV routing protocol is less. Figure 8 (e) shows the variation of Packet Delivery Ratio with packet size 1000 bytes. The packet delivery ratio is more in DSR routing protocol. The packet delivery ratio of DSDV routing protocol is less. The packet delivery ratio of AODV routing protocol lies between DSR and DSDV routing protocols. Figure 8 (c) shows the variation of throughput with packet size 512 bytes. When number of nodes are 10 and 20 the throughput of DSR routing protocol is more and DSDV is less. As the number of nodes increases the throughput of DSDV and AODV routing protocols increases and maximum for AODV routing protocol. Figure 8 (f) shows the variation of throughput with packet size 1000 bytes. As the number of nodes increases the throughput of DSR routing protocol.

\subsection{Performance Analysis by Varying Number of Nodes under TCP and FTP Traffic with 512 Bytes and 1000 Bytes Packet Size}

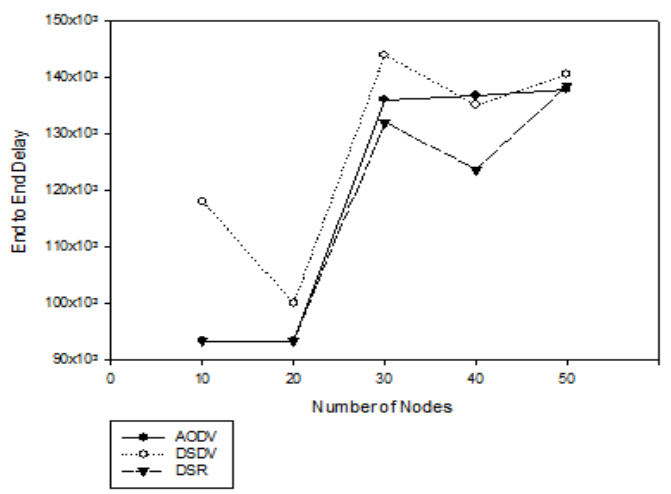

(a) End-to-End Delay (512 bytes)

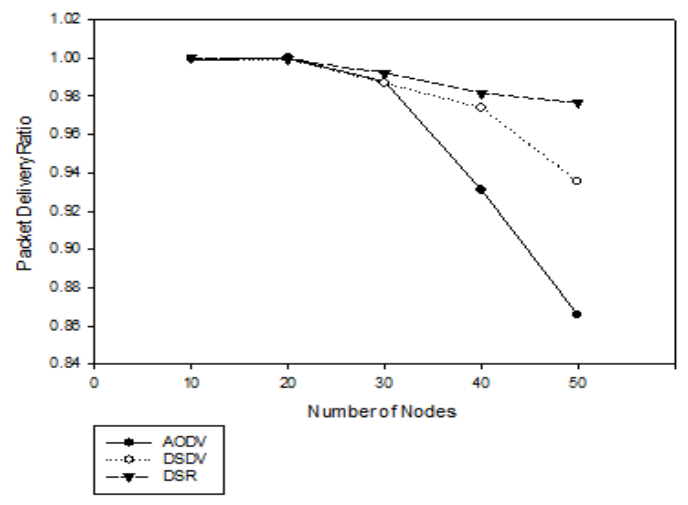

(b) Packet Delivery Ratio (512 bytes) 


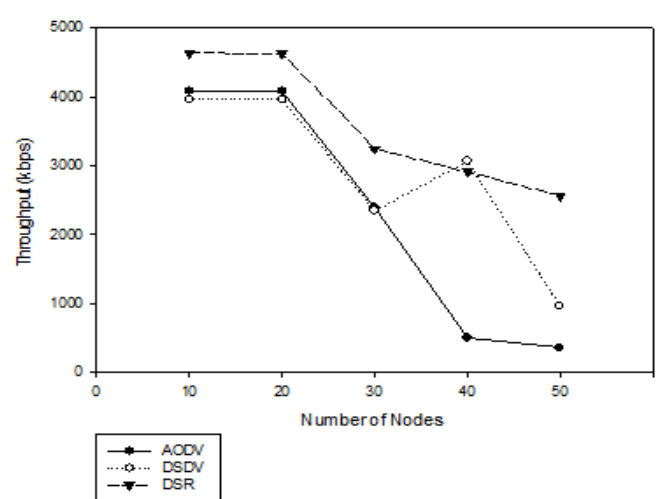

(c) Throughput (512 bytes)

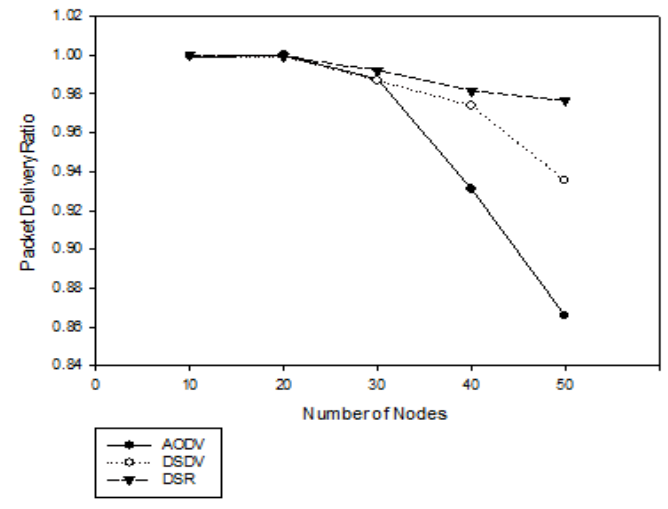

(e) Packet Delivery Ratio (1000 bytes)

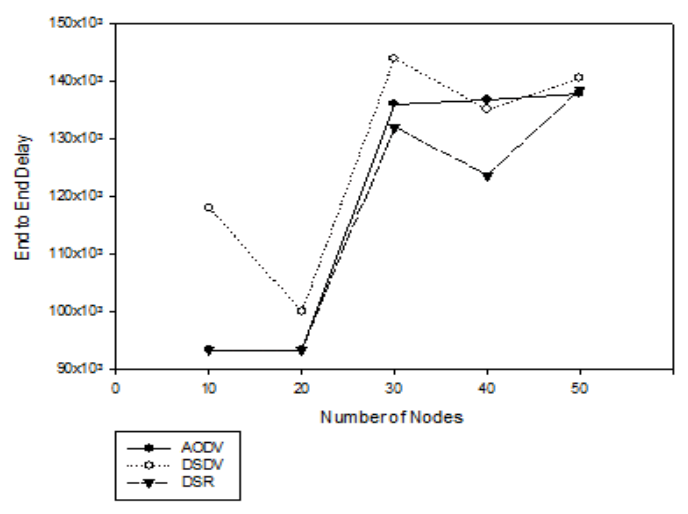

(d) End-to-End Delay (1000 bytes)

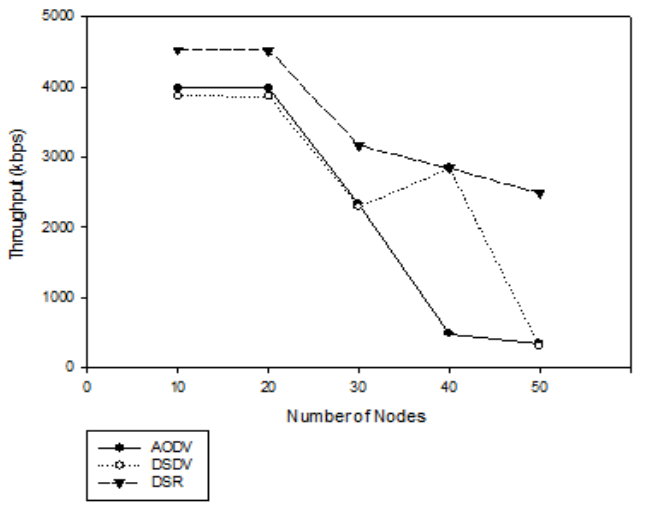

(f) Throughput (1000 bytes)

Figure 9. Performance Analysis under TCP and FTP Traffic by Varying Number of Nodes and Packet Size (a) Variation of End-to-End Delay (512 bytes) (b) Variation of Packet Delivery Ratio (512 bytes) (c) Variation of throughput (512 bytes) (d) Variation of End-to-End Delay (1000 bytes) (e) Variation of Packet Delivery Ratio (1000 bytes) (f) Variation of throughput (1000 bytes)

\subsubsection{Number of Node Analysis}

Figure 9 shows the performance analysis of AODV, DSR and DSDV routing protocol under TCP and FTP traffic by varying number of nodes with different packet sizes. In Figure 9 (a) and Figure 9 (d) the variation of End-to-End Delay is shown with packet size 512 bytes and 1000 bytes. The delay has no effect of packet size. The values of delay remain the same with 512 and 1000 bytes packet sizes. The delay is more in DSDV routing protocol and increases as the number of nodes increases. The delay of DSR routing protocol is less and AODV routing protocol lies in between DSDV and DSR. Figure 9 (b) and Figure 9 (e) shows the variation of Packet Delivery Ratio with packet size 512 bytes and 1000 bytes. The effect of 512 bytes and 1000 bytes packet sizes remains the same. The packet delivery ratio of DSR routing protocol is more and packet delivery ratio of AODV routing protocol is less. Figure 8 (c) shows the variation of throughput with packet size 512 bytes. DSR routing protocol throughput is more. The throughput of AODV routing protocol is less then DSDV and DSR routing protocols. In Figure 8 (f) the variation of throughput with packet size 1000 bytes is shown. When the packet size in 1000 bytes the DSR routing protocol gives more throughput and AODV gives less throughput. 
4.6. Performance Analysis by Varying Number of Nodes under UDP and CBR Traffic with 512 Bytes and 1000 Bytes Packet Size

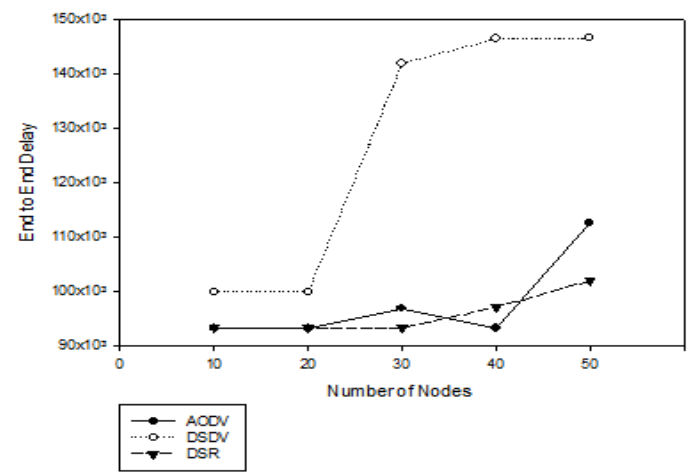

(a) End-to-End Delay (512 bytes)

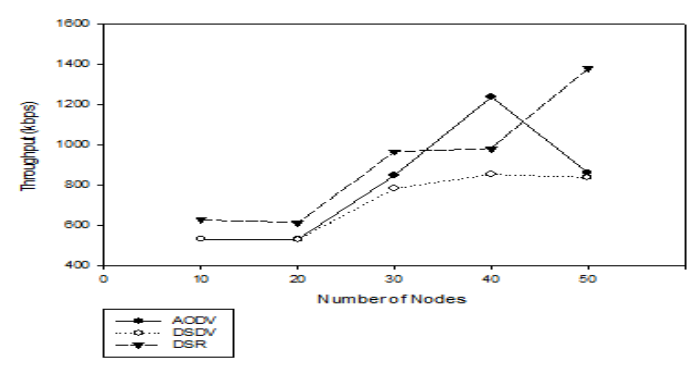

(c) Throughput (512 bytes)

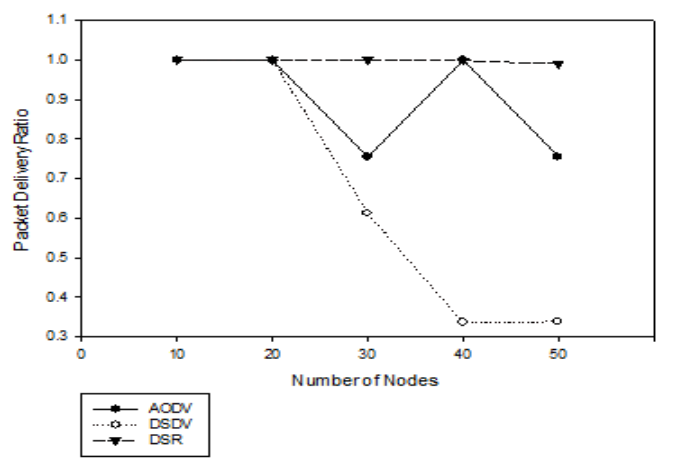

(e) Packet Delivery Ratio (1000 bytes)

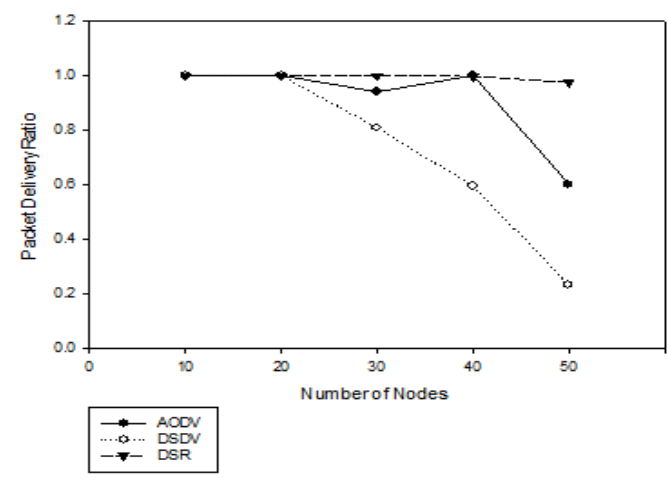

(b) Packet Delivery Ratio (512 bytes)

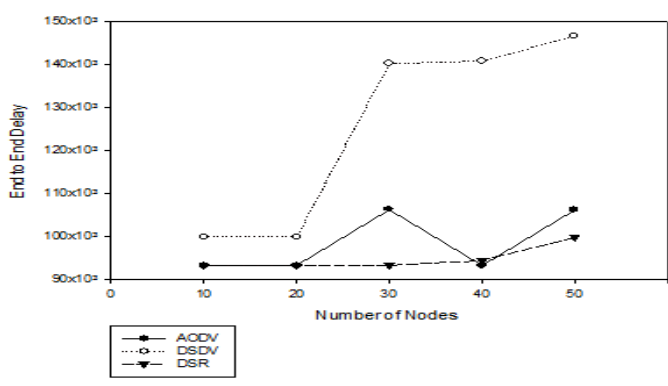

(d) End-to-End Delay (1000 bytes)

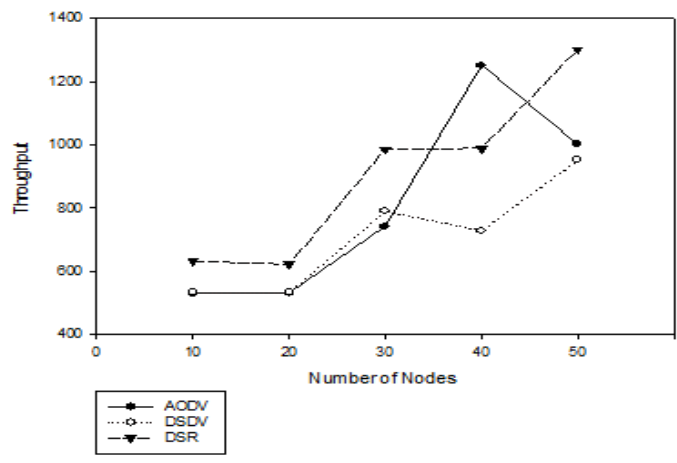

(f) Throughput (1000 bytes)

Figure 10. Performance Analysis under UDP and CBR Traffic by Varying Number of Nodes and Packet Size (a) Variation of End-to-End delay (512 bytes) (b) Variation of packet delivery ratio (512 bytes) (c) Variation of throughput (512 bytes) (d) Variation of end-to-end delay (1000 bytes) (e) Variation of packet delivery ratio (1000 bytes) (f) Variation of throughput (1000 bytes)

\subsubsection{Number of Node Analysis}

Figure (10) shows the performance analysis of AODV, DSR and DSDV routing protocols under UDP and CBR traffic condition by varying number of nodes and packet size. Figure 10 (a) shows the variation of End-to-End delay with packet size 512 bytes. The delay in DSDV routing protocol is more than DSR and AODV routing protocols. Figure 10 (d) shows the variation of End-to-End Delay with packet size 1000 bytes. The 
delay is more in DSDV routing protocol and less in DSR routing. Figure 10 (b) shows the variation of Packet Delivery Ratio with packet size 512 bytes. DSR routing protocol delivers more packets so its Packet Delivery Ratio is more and DSDV routing protocol delivers less packets so its Packet delivery ratio is less. In Figure 10 (e) the variation of Packet Delivery Ratio with packet size 1000 bytes is shown. Again the packet delivery ratio of DSR routing protocol is more and DSDV routing protocol is less. Figure 10 (c) shows the variation of throughput with packet size 512 bytes. The throughput of DSR routing protocol is more when number of nodes are 10,20,30 and 50. The DSDV routing protocol gives less throughput. Figure 10 (f) shows the variation of throughput with packet size 1000 bytes. Again with 1000 bytes of packet size the DSR routing protocol gives more throughput and DSDV routing protocol gives less throughput.

Table 1. Simulation Parameters and Values

\begin{tabular}{|l|l|}
\hline SIMULATION PARAMETERS & VALUE \\
\hline Channel & Wireless \\
\hline Propagation Model & Two Ray Ground \\
\hline Mac Address & 802.11 \\
\hline Packet Size & 512 bytes and 1000 bytes \\
\hline Duration & 150 sec \\
\hline Routing Protocols & AODV, DSR, DSDV \\
\hline Agents & TCP and UDP \\
\hline Traffic Conditions & CBR and FTP \\
\hline Simulation Area (sq. m) & $200,400,600,800,1000$ \\
\hline Number of nodes & $10,20,30,40,50$ \\
\hline
\end{tabular}

\section{Conclusion}

In this paper the performance analysis of AODV, DSR and DSDV routing protocol is carried out under different traffic conditions with different packet sizes. The performance analysis is carried out by varying network size and number of nodes under each traffic condition with 512 and 1000 bytes packet size. The three measuring parameters i.e. Endto-End Delay, Packet Delivery Ratio and Throughput are used to analyze the performance of routing protocols. The performance of AODV, DSR and DSDV routing protocol varies under different traffic conditions. The data packet size also affects the performance of routing protocols. The protocols perform different under FTP and CBR traffic conditions. It affects the quality of service of routing protocols. The performance of DSR routing protocol is better in different traffic condition i.e., with TCP and CBR, TCP and FTP, UDP and CBR. The DSR routing protocol is better option to apply in real applications. 
Table 2. Performance Analysis of DSR, AODV and DSDV Routing Protocols by Varying Network Size under Different Traffic Conditions with 512 Bytes Packet Size

\begin{tabular}{|c|c|c|c|c|c|c|c|c|c|c|}
\hline \multirow{7}{*}{$\begin{array}{l}\mathrm{TCl} \\
\text { and } \\
\mathrm{CBI}\end{array}$} & \multicolumn{4}{|c|}{ DSR } & \multicolumn{3}{|c|}{ AODY } & \multicolumn{3}{|c|}{ DSDV } \\
\hline & \begin{tabular}{|c|} 
Netwooks \\
Size
\end{tabular} & $\begin{array}{c}\text { Throughput } \\
\text { (sbps) }\end{array}$ & \begin{tabular}{|l|}
$P D R$ \\
\end{tabular} & Delay & $\begin{array}{c}\text { Throughput } \\
\text { (kbps) }\end{array}$ & \begin{tabular}{|l|l|}
$P D R$ \\
\end{tabular} & Delay & $\begin{array}{c}\text { Throughput } \\
\text { (kbps) }\end{array}$ & PDR & Delay \\
\hline & 200 & 1241.92 & 1.0000 & 93294.9 & 105890 & 1.0000 & 93250.6 & 1062.66 & 1.0000 & 99958.1 \\
\hline & 400 & 1240.33 & 1.0000 & 93291 & 1060.09 & 1.0000 & 932389 & 1061.91 & 1.0000 & 999572 \\
\hline & 600 & 1947.24 & 1.0000 & 933943 & 2344.64 & 0.9992 & 104885 & 2024.03 & 0.9888 & 141729 \\
\hline & 800 & 3334.43 & 0.9893 & 139519 & 1827.84 & 1.0000 & 952259 & 1035.86 & 0.9565 & 146387 \\
\hline & 1000 & 1023.72 & 0.9604 & 139066 & 242.78 & 0.9511 & 139452 & 2849.96 & 0.8767 & 120481 \\
\hline \multirow{7}{*}{$\begin{array}{l}\text { ICP } \\
\text { and } \\
\text { FTP }\end{array}$} & \multicolumn{4}{|c|}{ DSR } & \multicolumn{3}{|c|}{ AODV } & \multicolumn{3}{|c|}{ DSDV } \\
\hline & $\begin{array}{l}\text { Netwook } \\
\text { Size }\end{array}$ & $\begin{array}{c}\text { Throughput } \\
\text { (kbps) }\end{array}$ & $\begin{array}{l}P D R \\
\end{array}$ & Delay & $\begin{array}{c}\text { Throughput } \\
\text { (kbps) }\end{array}$ & \begin{tabular}{|l|l|} 
PDR \\
\end{tabular} & Delay & $\begin{array}{c}\text { Throughput } \\
\text { (kbps) }\end{array}$ & PDR & Delay \\
\hline & 200 & 4633.19 & 1.0000 & 933863 & 4077.94 & 1.0000 & 933939 & 3949.09 & 1.0000 & 100033 \\
\hline & 400 & 4631.13 & 0.9995 & 933992 & 4075.74 & 1.0000 & 93377.1 & 3944.19 & 0.9994 & 100042 \\
\hline & 600 & 3243.01 & 0.9921 & \begin{tabular}{|l|l|l}
132110 \\
\end{tabular} & 2390.46 & 0.9874 & 136033 & 2344.18 & 0.9870 & 144018 \\
\hline & 800 & 2725.58 & 0.9962 & 112222 & 2819.95 & 0.9804 & 131729 & 1657.16 & 0.9606 & 136972 \\
\hline & 1000 & 2749.58 & 0.9901 & 139222 & 605.19 & 0.8954 & 138692 & 2849.96 & 0.876 & 120481 \\
\hline \multirow{7}{*}{$\begin{array}{l}\text { CDP } \\
\text { and } \\
\text { CBR }\end{array}$} & \multicolumn{4}{|c|}{ DSR } & \multicolumn{3}{|c|}{ AODY } & \multicolumn{3}{|c|}{ DSDV } \\
\hline & \begin{tabular}{|l} 
Netwook \\
Sizze
\end{tabular} & Throughput & $\begin{array}{l}P D R \\
\end{array}$ & Delay & Throughput & PDR & Delay & Throughput & $P D R$ & Delay \\
\hline & 200 & 620.34 & 1.0000 & 93297.1 & 532.20 & 1.0000 & 93284.7 & 526.47 & 1.0000 & 99996.4 \\
\hline & 400 & 620.84 & 1.0000 & 93283.1 & 532.20 & 1.0000 & 93284.5 & 526.52 & 1.0000 & 100007 \\
\hline & 600 & 967.89 & 1.0000 & \begin{tabular}{|l|l}
93370.8 \\
\end{tabular} & 848.58 & 0.9408 & 969212 & 784.62 & 0.8094 & 141949 \\
\hline & 800 & 977.11 & 0.9997 & 946516 & 884.20 & 1.0000 & 932953 & 739.81 & 0.5018 & 146630 \\
\hline & 1000 & 1295.65 & 0.9894 & 98326.5 & 1567.42 & 0.9763 & 951292 & 987.49 & 0.0975 & 141866 \\
\hline
\end{tabular}


Table 3. Performance Analysis of DSR, AODV and DSDV Routing Protocols by Varying Network Size under Different Traffic Conditions with 1000 Bytes Packet Size

\begin{tabular}{|c|c|c|c|c|c|c|c|c|c|c|}
\hline \multirow{7}{*}{$\begin{array}{l}\text { TCP } \\
\text { and } \\
\text { CBR }\end{array}$} & \multicolumn{4}{|c|}{ DSR } & \multicolumn{3}{|c|}{ AODV } & \multicolumn{3}{|c|}{ DSDV } \\
\hline & $\begin{array}{c}\text { Network } \\
\text { Size }\end{array}$ & $\begin{array}{c}\text { Throughput } \\
\text { (kbps) }\end{array}$ & PDR & Delay & $\begin{array}{l}\text { Throughput } \\
\text { (kbps) }\end{array}$ & PDR & Delay & $\begin{array}{c}\text { Throughput } \\
\text { (kbps) }\end{array}$ & PDR & Delay \\
\hline & 200 & 621.69 & 1.0000 & 93255.9 & 538.37 & 1.0000 & 93211.4 & 534.50 & 1.0000 & 99920.7 \\
\hline & 400 & 624.95 & 1.0000 & 93246.9 & 538.37 & 1.0000 & 93211.4 & 534.50 & 1.0000 & 99920.7 \\
\hline & 600 & 978.26 & 1.0000 & 93333.6 & 893.39 & 1.0000 & 95156.1 & 1291.04 & 0.9705 & 140047 \\
\hline & 800 & 1147.33 & 0.9994 & 96230.4 & 893.60 & 1.0000 & 95192.1 & 1285.10 & 0.9921 & 132870 \\
\hline & 1000 & 1747.19 & 0.9886 & 110981 & 279.25 & 0.8543 & 138542 & 549.15 & 0.9026 & 131032 \\
\hline \multirow{7}{*}{$\begin{array}{l}\text { TCP } \\
\text { and } \\
\text { FTP }\end{array}$} & \multicolumn{4}{|c|}{ DSR } & \multicolumn{3}{|c|}{ AODV } & \multicolumn{3}{|c|}{ DSDV } \\
\hline & $\begin{array}{c}\text { Network } \\
\text { Size }\end{array}$ & $\begin{array}{l}\text { Throughput } \\
\text { (kbps) }\end{array}$ & PDR & Delay & $\begin{array}{l}\text { Throughput } \\
\text { (kbps) }\end{array}$ & PDR & Delay & $\begin{array}{c}\text { Throughput } \\
\text { (kbps) }\end{array}$ & PDR & Delay \\
\hline & 200 & 4524.60 & 1.0000 & 93386.3 & 3982.36 & 1.0000 & 93393.9 & 3856.53 & 1.0000 & 100033 \\
\hline & 400 & 4522.59 & 0.9995 & 93399.2 & 3980.22 & 1.0000 & 93377.1 & 3851.75 & 0.9994 & 100042 \\
\hline & 600 & 3166.92 & 0.9921 & 132110 & 2334.38 & 0.9874 & 136033 & 2170.35 & 0.9870 & 144018 \\
\hline & 800 & 2661.43 & 0.9962 & 112222 & 2753.63 & 0.9804 & 131729 & 1502.81 & 0.9606 & 136972 \\
\hline & 1000 & 2635.14 & 0.9901 & 139222 & 590.71 & 0.8954 & 138692 & 1966.82 & 0.8767 & 120481 \\
\hline \multirow{7}{*}{$\begin{array}{l}\text { UDP } \\
\text { and } \\
\text { CBR }\end{array}$} & \multicolumn{4}{|c|}{ DSR } & \multicolumn{3}{|c|}{ AODV } & \multicolumn{3}{|c|}{ DSDV } \\
\hline & $\begin{array}{c}\text { Network } \\
\text { Size }\end{array}$ & $\begin{array}{c}\text { Throughput } \\
\text { (kbps) }\end{array}$ & PDR & Delay & $\begin{array}{c}\text { Throughput } \\
\text { (kbps) }\end{array}$ & PDR & Delay & $\begin{array}{c}\text { Throughput } \\
\text { (kbps) }\end{array}$ & PDR & Delay \\
\hline & 200 & 626.76 & 1.0000 & 93215.3 & 530.63 & 1.0000 & 93241.5 & 537.06 & 1.0000 & 99973.1 \\
\hline & 400 & 624.98 & 1.0000 & 93241.6 & 530.63 & 1.0000 & 93241.3 & 537.06 & 1.0000 & 99973.1 \\
\hline & 600 & 985.77 & 1.0000 & 93384.3 & 741.57 & 0.7553 & 106307 & 788.92 & 0.6119 & 140291 \\
\hline & 800 & 982.19 & 1.0000 & 93754.2 & 899.51 & 1.0000 & 93272.7 & 773.65 & 0.6272 & 141147 \\
\hline & 1000 & 1314.12 & 0.9929 & 98627.2 & 1605.19 & 0.9924 & 95088.9 & 3312.27 & 0.0858 & 141885 \\
\hline
\end{tabular}

Table 4. Performance Analysis of DSR, AODV and DSDV Routing Protocols by Varying Number of Nodes under Different Traffic Conditions with 512 Bytes Packet Size

\begin{tabular}{|c|c|c|c|c|c|c|c|c|c|c|}
\hline \multirow{7}{*}{$\begin{array}{l}\text { TCP } \\
\text { and } \\
\text { CBR }\end{array}$} & \multicolumn{4}{|c|}{ DSR } & \multicolumn{3}{|c|}{ AODV } & \multicolumn{3}{|c|}{ DSDV } \\
\hline & $\begin{array}{l}\text { No of } \\
\text { Nodes }\end{array}$ & $\begin{array}{c}\text { Throughput } \\
\text { (kbps) }\end{array}$ & PDR & Delay & $\begin{array}{c}\text { Throughput } \\
\text { (kbps) }\end{array}$ & PDR & Delay & $\begin{array}{c}\text { Throughput } \\
\text { (kbps) }\end{array}$ & PDR & Delay \\
\hline & 10 & 1241.53 & 1.0000 & 93301.3 & 1059.25 & 1.0000 & 93249 & 1063.37 & 1.0000 & 99983.9 \\
\hline & 20 & 1238.55 & 1.0000 & 93306.4 & 1057.36 & 1.0000 & 93230.6 & 1047.42 & 1.0000 & 99969.5 \\
\hline & 30 & 1947.24 & 1.0000 & 93394.3 & 2344.64 & 0.9992 & 104885 & 2024.03 & 0.9888 & 141729 \\
\hline & 40 & 1945.30 & 0.9998 & 95323 & 2478.57 & 1.0000 & 93258.6 & 2248.11 & 0.9695 & 143092 \\
\hline & 50 & 1957.18 & 0.9653 & 139160 & 1292.28 & 0.9381 & 124607 & 405.78 & 0.1429 & 115007 \\
\hline \multirow{7}{*}{$\begin{array}{l}\text { TCP } \\
\text { and } \\
\text { FTP }\end{array}$} & \multicolumn{4}{|c|}{ DSR } & \multicolumn{3}{|c|}{ AODV } & \multicolumn{3}{|c|}{ DSDV } \\
\hline & $\begin{array}{l}\text { No of } \\
\text { Nodes }\end{array}$ & $\begin{array}{c}\text { Throughput } \\
\text { (kbps) }\end{array}$ & PDR & Delay & $\begin{array}{c}\text { Throughput } \\
\text { (kbps) }\end{array}$ & PDR & Delay & $\begin{array}{c}\text { Throughput } \\
\text { (kbps) }\end{array}$ & PDR & Delay \\
\hline & 10 & 4633.52 & 0.9999 & 93398.9 & 4079.22 & 0.9994 & 93400.2 & 3960.10 & 0.9995 & 118089 \\
\hline & 20 & 4629.65 & 0.9995 & 93400.1 & 4075.95 & 1.0000 & 93373.7 & 3957.54 & 0.9994 & 100043 \\
\hline & 30 & 3243.01 & 0.9921 & 132110 & 2390.46 & 0.9874 & 136033 & 2344.18 & 0.9870 & 144018 \\
\hline & 40 & 2910.67 & 0.9816 & 123747 & 495.85 & 0.9309 & 136735 & 3064.34 & 0.9740 & 135200 \\
\hline & 50 & 2561.01 & 0.9766 & 138519 & 354.41 & 0.8655 & 137837 & 966.38 & 0.9355 & 140528 \\
\hline \multirow{7}{*}{$\begin{array}{l}\text { UDP } \\
\text { and } \\
\text { CBR }\end{array}$} & \multicolumn{4}{|c|}{ DSR } & \multicolumn{3}{|c|}{ AODV } & \multicolumn{3}{|c|}{ DSDV } \\
\hline & $\begin{array}{l}\text { No of } \\
\text { Nodes }\end{array}$ & $\begin{array}{c}\text { Throughput } \\
\text { (kbps) }\end{array}$ & PDR & Delay & $\begin{array}{c}\text { Throughput } \\
\text { (kbps) }\end{array}$ & PDR & Delay & $\begin{array}{c}\text { Throughput } \\
\text { (kbps) }\end{array}$ & PDR & Delay \\
\hline & 10 & 628.53 & 1.0000 & 93301.8 & 532.61 & 1.0000 & 93296.9 & 532.65 & 1.0000 & 99989.1 \\
\hline & 20 & 614.91 & 1.0000 & 93287.1 & 532.25 & 1.0000 & 93297.7 & 530.89 & 1.0000 & 99987 \\
\hline & 30 & 967.89 & 1.0000 & 93370.8 & 848.58 & 0.9408 & 96921.2 & 784.62 & 0.8094 & 141949 \\
\hline & 40 & 983.15 & 0.9980 & 97179.3 & 1239.56 & 1.0000 & 93295.6 & 854.24 & 0.5964 & 146493 \\
\hline & 50 & 1380.44 & 0.9756 & 101972 & 861.45 & 0.6017 & 112672 & 838.52 & 0.2338 & 146625 \\
\hline
\end{tabular}




\section{Table 5: Performance Analysis of DSR, AODV and DSDV Routing Protocols by Varying Number of Nodes under Different Traffic Conditions with 1000 Bytes Packet Size}

\begin{tabular}{|c|c|c|c|c|c|c|c|c|c|c|}
\hline \multirow{7}{*}{$\begin{array}{l}\text { TCP } \\
\text { and } \\
\text { CBR }\end{array}$} & \multicolumn{4}{|c|}{ DSR } & \multicolumn{3}{|c|}{ AODV } & \multicolumn{3}{|c|}{ DSDV } \\
\hline & $\begin{array}{l}\text { No of } \\
\text { Nodes }\end{array}$ & $\begin{array}{l}\text { Throughput } \\
\text { (kbps) }\end{array}$ & PDR & Delay & $\begin{array}{l}\text { Throughput } \\
\text { (kbps) }\end{array}$ & PDR & Delay & $\begin{array}{c}\text { Throughput } \\
\text { (kbps) }\end{array}$ & PDR & Delay \\
\hline & 10 & 619.66 & 1.0000 & 93268.2 & 539.10 & 1.0000 & 93203.7 & 532.88 & 1.0000 & 99964.1 \\
\hline & 20 & 623.94 & 1.0000 & 93221.8 & 538.74 & 1.0000 & 93207.7 & 534.27 & 1.0000 & 99963.9 \\
\hline & 30 & 978.26 & 1.0000 & 93333.6 & 893.39 & 1.0000 & 95156.1 & 986.89 & 0.9781 & 142051 \\
\hline & 40 & 1144.58 & 0.9994 & 96237.9 & 1786.65 & 0.9539 & 132397 & 853.46 & 0.9881 & 138914 \\
\hline & 50 & 1331.11 & 1.0000 & 93334.1 & 1397.44 & 0.9455 & 137407 & 743.87 & 0.9174 & 113901 \\
\hline \multirow{7}{*}{$\begin{array}{l}\text { TCP } \\
\text { and } \\
\text { FTP }\end{array}$} & \multicolumn{4}{|c|}{ DSR } & \multicolumn{3}{|c|}{ AODV } & \multicolumn{3}{|c|}{ DSDV } \\
\hline & $\begin{array}{l}\text { No of } \\
\text { Nodes }\end{array}$ & $\begin{array}{l}\text { Throughput } \\
\text { (kbps) }\end{array}$ & PDR & Delay & $\begin{array}{l}\text { Throughput } \\
\text { (kbps) }\end{array}$ & PDR & Delay & $\begin{array}{l}\text { Throughput } \\
\text { (kbps) }\end{array}$ & PDR & Delay \\
\hline & 10 & 4524.92 & 0.9999 & 93398.9 & 3983.61 & 0.9994 & 93400.2 & 3867.28 & 0.9995 & 118089 \\
\hline & 20 & 4521.14 & 0.9995 & 93400.1 & 3980.42 & 1.0000 & 93373.7 & 3864.79 & 0.9994 & 100043 \\
\hline & 30 & 3166.92 & 0.9921 & 132110 & 2334.38 & 0.9874 & 136033 & 2289.15 & 0.9870 & 144018 \\
\hline & 40 & 2842.14 & 0.9816 & 123747 & 483.92 & 0.9309 & 136735 & 2840.06 & 0.9740 & 135200 \\
\hline & 50 & 2491.21 & 0.9766 & 138519 & 344.33 & 0.8655 & 137837 & 307.70 & 0.9435 & 145252 \\
\hline \multirow{7}{*}{$\begin{array}{l}\text { UDP } \\
\text { and } \\
\text { CBR }\end{array}$} & \multicolumn{4}{|c|}{ DSR } & \multicolumn{3}{|c|}{ AODV } & \multicolumn{3}{|c|}{ DSDV } \\
\hline & $\begin{array}{l}\text { No of } \\
\text { Nodes }\end{array}$ & Throughput & PDR & Delay & Throughput & PDR & Delay & Throughput & PDR & Delay \\
\hline & 10 & 631.03 & 1.0000 & 93240 & 530.37 & 1.0000 & 93277.4 & 532.53 & 1.0000 & 99993.2 \\
\hline & 20 & 622.09 & 1.0000 & 93263.1 & 531.23 & 1.0000 & 93247.5 & 533.35 & 1.0000 & 99959.4 \\
\hline & 30 & 985.77 & 1.0000 & 93384.3 & 741.57 & 0.7553 & 106307 & 788.92 & 0.6119 & 140291 \\
\hline & 40 & 989.18 & 0.9987 & 94390.3 & 1249.75 & 1.0000 & 93272.3 & 728.19 & 0.3361 & 140833 \\
\hline & 50 & 1301.05 & 0.9903 & 99777.8 & 1000.85 & 0.7550 & 106272 & 951.40 & 0.3389 & 146638 \\
\hline
\end{tabular}

The performance of DSR routing protocol is good with different measuring parameters. DSR protocol is the better solution for every traffic condition. In future, we increase the quality of service of DSR protocol by purposed a enhance version of DSR protocol named Multipath DSR. Multipath DSR make the existing protocol more reliable and efficient.

\section{References}

[1] A Tuteja, A Gujral and A Thalia, Comparative Performance Analysis of DSDV, AODV and DSR Routing Protocols in MANET using NS2, IEEE Comp. Society, (2010), pp. 330-333.

[2] N Sharma, S Rana and R.M. Sharma, "Provisioning of Quality of Service in MANETs performance analysis \& comparison (AODV and DSR)" IEEE 2nd International Conference on Computer Engineering and Technology (ICCET), (2010).

[3] M. M. Morshed, F. I. S. Ko, Lim Dongwook and M. H. Rahman, "Performance evaluation of DSDV and AODV routing protocols in Mobile Ad-Hoc Networks", IEEE 4th International Conference on New Trends in Information Science and Service Science (NISS), (2010).

[4] Z. Ismail and R. Hassan, "Performance of AODV routing protocol in Mobile Ad Hoc Network", IEEE, International Symposium of Information Technology (ITSim), (2010).

[5] A. D. Robins, "GAWK: an effective AWK programming, 3rd Ed, (2010) April.

[6] G. S. Tomar, T. Sharma, D. Bhattacharyya and Kim Tai-hoon, "Performance Comparison of AODV, DSR and DSDV under Various Network Conditions" A Survey, IEEE, International Conference on Ubiquitous Computing and Multimedia Applications (UCMA), (2011).

[7] S. Mohapatra and P. Kanungo, "Performance analysis of AODV, DSR, OLSR and DSDV Routing Protocols using NS2 Simulator", International Conference on Communication Technology and System Design, (2011).

[8] A. Aggarwal, S. Gandhi and N. Chaubey, "Performance Analysis of AODV, DSDV and DSR in MANETS", International Journal of Distributed and Parallel Systems (IJDPS), vol. 2, (2011).

[9] D. B. Rao, K. Sreenu and P. Kalpana, "A Study on Dynamic Source Routing Protocol for Wireless Ad Hoc Networks", International Journal of Advance Research in Computer and Communication Engineering, vol. 1, issue 8, (2012).

[10] A. Bagwari, R. Jee, P. Joshi and S. Bisht, "Performance of AODV Routing Protocol with Increasing the MANET Nodes and it's Effects on QOS of Mobile Ad Hoc Networks", IEEE, International Conference on Communication Systems and Network Technologies (CSNT), (2012) May.

[11] M. S. Chaudhary and V. Singh, "Simulation and Analysis of Routing Protocol under CBR and TCP Traffic Source", IEEE, Communication Systems and Network Technologies (CSNT), (2012). 
[12] D. Kampitaki and A. Anastasios, "Economides, Simulation study of MANET routing protocols under FTP traffic", ELSEVIER, Conference on Electronics, Telecommunications and Computers-CETC, (2013).

[13] S. Liu, Y. Yang and W. Wang, "Research of AODV Routing Protocol for Ad Hoc Networks, ELSEVIER, and AASRI Conference on Parallel and Distributed Computing and Systems, (2013).

[14] R. Sharma and S. Sabharwal, "Dynamic Source Routing Protocol (DSR)", International Journal of Advance Research in Computer Science and Software Engineering, vol. 3, no. 7, (2013).

[15] Q. Razouqi, A. Bousheri, M. Gaballah and L. Alsaleh, "Extensive Simulation Performance Analysis for DSDV, DSR and AODV MANET Routing Protocols", IEEE, 27th International Conference on Advanced Information Networking and Applications Workshops (WAINA), (2013) March.

[16] T. K. Araghi, M. Zamani and A. B. T. A. Mnaf, "Performance Analysis in Reactive Routing Protocols in Wireless Mobile Ad Hoc Networks Using DSR, AODV and AOMDV", IEEE, International Conference on Informatics and Creative Multimedia (ICICM), (2013) September.

[17] Papadopoulos, Mavromoustakis, Skourletopoulos, Mastorakis and Pallis, "Performance analysis of reactive routing protocols in Mobile Ad hoc Networks", IEEE, International Conference on Telecommunications and Multimedia (TEMU), (2014) July.

[18] R. Desai and B. P. Patil, "Analysis of routing protocols for Ad Hoc Networks", IEEE, Communication and Information Technology Applications (CSCITA), (2014).

[19] S. El Khediri, N. Nasri, A. Benfradj and A. Kachouri, "Routing protocols in MANET: Performance comparison of AODV, DSR and DSDV protocols using NS2, Networks", IEEE, International Symposium on Computers and Communications, (2014) June.

[20] P. Rajankumar, P. Nimisha and P. Kamboj, "A Comparative study and simulation of AODV MANET routing protocol in NS2 \& NS3", IEEE, International Conference on Computing for Sustainable Global Development (INDIAcom), (2014) March.

[21] B. Karthikeyan, N. Kanimozhi and S. H. Ganesh, "Analysis of Reactive AODV Routing Protocol for MANET", IEEE, World Congress on Computing and Communication Technologies (WCCCT), (2014) March.

[22] S. El Khediri, N. Nasri, A. Benfradj, A. Kachouri and A. Wei, "Routing protocols in MANET: Performance comparison of AODV, DSR and DSDV protocols using NS2" IEEE, International Symposium on Networks, Computers and Communication, (2014) June.

[23] Q. Razouqi, M. Gaballah and L. Alsaleh, "Combined traffic simulation scenarios performance investigation routing protocols AODV, DSR and DSDV in MANET", IEEE, 8th International Conference on Computer Engineering (ICENCO), (2012).

\section{Authors}

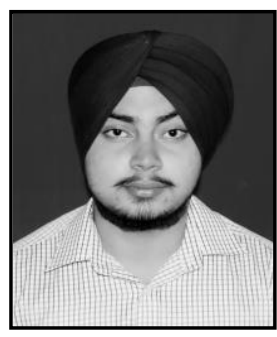

Barinderpal Singh, Research Scholar Computer Science \& Engineering Department from DAV University Jalandhar, Punjab (INDIA). B.Tech. Professional with specialization in Information Technology from SBBSIET (PTU) Jalandhar, Punjab (INDIA). Member of Computer Society of India. Participated in Paper Presentation organized during National Conference on impact of Science and tech. Research Publications in various international journals.

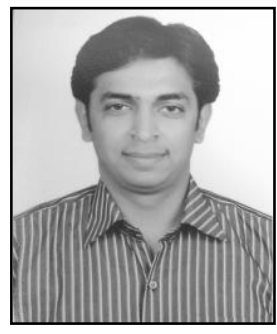

Rahul Hans, he is working as assistant professor in the Department of computer Science and Engineering at DAV University, Jalandhar Punjab (INDIA). He has done his M.Tech in Computer Science and Engineering from Guru Nanak Dev University, Amritsar (INDIA). His research areas include Networking, Operating systems, Distributed computing, Mobile agents. He has various research publications in various international conferences and journal and also presented several papers in various national and international conferences. 
International Journal of Future Generation Communication and Networking Vol. 8, No. 2 (2015) 